\title{
Los sistemas silvopastoriles en Cuba
}

\section{Silvopastoral systems in Cuba}

\author{
Iglesias JM y Giraldo JM ${ }^{1}$ \\ Colaboradores: L. Simón, L. Lamela ${ }^{1}$, D. Hernández, I. Hernández, Milagros \\ Milera ${ }^{1}$, Tania Sánchez ${ }^{1}$ y E. Castillo ${ }^{2}{ }^{1}$ Estación Experimental de Pastos y Forrajes \\ "Indio Hatuey ", Central España Republicana, CP 44280, Matanzas, Cuba. \\ ${ }^{2}$ Instituto de Ciencia Animal, La Habana, Cuba \\ iglesias@indio.atenas.inf.cu
}

CONFERENCIA DEL I SEMINARIO INTERNACIONAL DE GANADERÍA AGROECOLÓGICA REALIZADO EN VILLAVICENCIO COLOMBIA11 y 12 de noviembre de 2010

\section{RESUMEN}

El pastoreo del ganado en gramíneas naturales y mejoradas, así como el uso de los recursos proteicos forrajeros provenientes de la contribución de los árboles y los arbustos, es tan antiguo como su propia existencia. Sin embargo, los sistemas modernos de producción ganadera derivaron hacia el uso de tecnologías intensivas, basadas en otros recursos energético-proteicos que pudieran reemplazar las dietas a base de pastos, o el empleo de sistemas de corte y acarreo de forraje en grandes áreas de monocultivo. En este contexto, una gran parte de la producción de carne de res en Cuba se realizaba en establos, con tecnologías de estabulación total o parcial, donde la melaza de caña de azúcar (en combinación con urea en diferentes proporciones) y los suplementos proteicos constituían la parte fundamental de la dieta de los animales; mientras que el uso de forrajes y el pastoreo restringido pasaban a un segundo plano. Para la producción de leche se mejoraron los rebaños lecheros desde el punto de vista racial, con la introducción de sangre Holstein desde los países europeos y Canadá, así como la infraestructura general mediante el desarrollo de unidades de producción con instalaciones de concreto y áreas de praderas y forrajes de 40-110 ha cubiertas por gramíneas. Sin embargo, para lograr la expresión del potencial lechero de los animales era necesario suplementar con concentrados importados y fertilizar las áreas de las gramíneas y los forrajes. Dichas tecnologías demostraron 
una gran insostenibilidad, debido a su agresividad contra el medio ambiente y su dependencia de los insumos externos, lo que resulta particularmente importante en las áreas tropicales donde se localizan los países de economías más pobres. En este contexto, la renovación e introducción de pastos apropiados, y adaptados a las condiciones edafoclimáticas locales, junto a la incorporación estratégica de plantas arbóreas y arbustivas en las áreas de pastoreo, parece ser una alternativa tecnológica que contribuiría a mejorar la producción bovina, disminuyendo el impacto negativo en los ecosistemas donde se desarrolla. Esto pudiera constituir una solución económicamente viable, que no produce daños al medio ambiente y es aceptada socialmente, cuyos beneficios a corto plazo se manifestarían en un incremento sostenido de la producción animal.

Palabras clave: Gramíneas, leguminosas, producción animal.

\section{ABSTRACT}

Cattle grazing on natural grasses and improved, and the use of feed protein resources from the contribution of trees and shrubs, is as old as his own existence. However, modern livestock production systems resulted to the use of intensive technologies, based on other protein-energy resources that could replace the grass-based diets or the use of cut and carry systems of forage over large areas of monoculture. In this context, much of the production of beef in Cuba took place in stables, with technologies of total or partial confinement, where sugar cane molasses (in combination with urea in different proportions) and protein supplements were part of the diet of the animals, while the use of limited grazing forage and passed the background. For improved milk production dairy herds from the racial point of view, with the introduction of Holstein blood from European countries and Canada as well as general infrastructure through the development of production units with specific facilities and areas of grassland 40-110 and forage grass has covered. However, to achieve expression of the dairy potential of the animals was necessary to supplement with imported concentrates and fertilize areas of grasses and forages. These technologies showed great unsustainable due to its aggression against the environment and dependence on external inputs, 
which is particularly important in tropical areas where countries are located in poorer economies. In this context, the renewal and introduction of appropriate grasses, adapted to local soil and climatic conditions, together with the strategic incorporation of tree and shrub plants in the grazing areas is an alternative technology that would improve cattle production, decreasing negative impact on the ecosystems in which it develops. This could be an economically viable solution, which causes damage to the environment and is socially accepted, whose shortterm benefits are manifest in a steady increase in animal production.

Keywords: Grasses, legumes, animal production.

\section{INTRODUCCIÓN}

Los sistemas agroforestales son un nombre colectivo para sistemas que involucren el uso de árboles y/o arbustos con cultivos y/o animales en la misma unidad de terreno (Kass, 1992). Entre los objetivos principales de estos sistemas se destacan: a) Aumentar la productividad vegetal y animal. b) Asegurar la sostenibilidad a través de la intensificación apropiada en el uso de la tierra. c) Diversificar la producción de alimentos. d) Producir madera, leña y otros materiales diversos que sirvan para la subsistencia del agricultor, el uso industrial o la exportación. e) Disminuir los riesgos del agricultor. f) Mitigar los efectos perjudiciales del sol, el viento y la lluvia sobre los suelos. g) Minimizar la escorrentía del agua y la pérdida del suelo. h) Combinar lo mejor de la experiencia tradicional con los conocimientos modernos.

Estos sistemas incluyen diversas modalidades y prácticas agrícolas, en las cuales hay interacciones ecológicas y económicas entre los componentes: árboles, animales y cultivos o pastos, lo que motiva su subdivisión en concordancia con el objetivo a alcanzar.

En este sentido, los sistemas silvopastoriles se presentan como una de dichas modalidades y por sus resultados y su proyección podría significar un importante paso en la estrategia de lograr la armonía entre la conservación ambiental y el desarrollo de la actividad ganadera. 
Según Bustamante y Romero, (1991) sus principales componentes son: los árboles y los arbustos, los pastos, los animales, el suelo y el subsuelo; éste último comprende los estratos del suelo no explorados por el pasto, pero sí potencialmente alcanzables por los árboles. La lluvia, la radiación solar, el dióxido de carbono y el nitrógeno atmosférico son parte de las entradas del sistema, al igual que los insumos agropecuarios como los fertilizantes y los plaguicidas.

Las salidas son los productos cosechables (leche, carne, lana, madera, leña, frutas y otros). Existen además las interacciones o servicios que dan al suelo, a las plantas y a los animales, tales como: sombra, disminución del viento y de la escorrentía, reciclaje de nutrimentos por parte de los árboles y los animales, así como pérdidas de energía y materiales

Hay algunas experiencias orientadas al diseño de alternativas agrosilvopastoriles que permiten intensificar las interacciones entre los árboles y los sistemas ganaderos basados en rumiantes (Simón, 1996; Iglesias, 1996; Hernández et al., 1998; Ruiz et al., 2000; Simón y Francisco, 2000, Iglesias, 2003, Mejías, 2008). Su principal objetivo es desarrollar alternativas tecnológicas para lograr la integración del complejo suelo-árbol-gramínea-animal, orientado a mejorar los niveles alimentarios y productivos de los animales, el uso racional de los recursos y la evaluación del impacto económico, social y medioambiental de las diferentes alternativas.

\section{FUNDAMENTOS Y PROPÓSITOS DE LOS SISTEMAS SILVOPASTORILES PARA LA PRODUCCIÓN ANIMAL EN CUBA}

Los sistemas silvopastoriles han sido desarrollados a partir de los resultados de las investigaciones que se realizaron desde la década de los ochenta, para mejorar la productividad de los pastos naturales a través de la introducción de valiosas especies herbáceas y leguminosas arbóreas. Esas investigaciones también determinaron los elementos esenciales del manejo de los pastos, tales como las cargas óptimas para los sistemas de bajos insumos y los métodos de pastoreo adecuados para lograr la sostenibilidad de los pastizales. 
De esta forma surge el llamado banco de proteína, en el cual se utiliza un manejo diferenciado de las leguminosas para propiciar su persistencia; así como las asociaciones múltiples de especies herbáceas y volubles con pastos naturales, que posteriormente fueron mejorados cuando se introdujeron al sistema los árboles, los arbustos y las gramíneas cultivadas, que fueron capaces de producir altas ganancias de peso vivo por día y por hectárea (Hernández et al., 1987; Hernández et al., 1988; Simón et al., 1990; Hernández et al., 1992, López, 2004, Simón, 2005, Sánchez, 2005, Reinoso, 2006).

Los propósitos y objetivos del desarrollo de los sistemas silvopastoriles para la producción ganadera son, entre otros, los siguientes:

1. Lograr ganancias diarias mínimas entre 500 y $600 \mathrm{~g} /$ animal y producciones de alrededor de $800 \mathrm{~kg}$ de carne por hectárea anualmente, con una carga cercana a las dos UGM en esta unidad de área.

2. Lograr potencialidades mínimas de 7-8 kg de leche/vaca/día o 14-16 kg de leche/ha/día, sin emplear suplementos energético-proteicos.

3. Obtener ganancias diarias entre 400 y $500 \mathrm{~g} / \mathrm{animal} / \mathrm{día}$ en novillas en crecimiento para reemplazo, lo que permite un peso de incorporación a la reproducción de $290-300 \mathrm{~kg}$, con edades que fluctúan entre 20 y 27 meses.

4. Alcanzar estos resultados con una rentabilidad notable, lograda en función del manejo racional y la explotación de las gramíneas con gastos mínimos en insumos.

5. Lograr la autosostenibilidad del sistema, propiciando la recirculación máxima de los nutrientes y la protección y el mantenimiento del medio ambiente.

Entre los diversos tipos de sistemas silvopastoriles desarrollados, los bancos de proteína y las asociaciones de árboles con gramíneas han mostrado los resultados más importantes en Cuba, en la producción tanto de carne como de leche, y se perfilan en la actualidad como sistemas que pueden ser generalizados, integrados al grupo de propósitos productivos de la crianza de ganado en el país. Sin 
embargo, otros como las cercas vivas, por ejemplo, con la ventaja de que son conocidas por su uso tradicional por los campesinos cubanos, pueden constituir una solución importante para reemplazar las cercas tradicionales de concreto en las unidades ganaderas, suministrando cercas más duraderas y económicas, y también contribuir como un recurso alimenticio de gran valor nutricional para el ganado.

¿Qué tipo de sistema debe utilizarse y cuáles deben ser las especies que formen la comunidad vegetal que caracteriza este nuevo tipo de enfoque del pastoreo? No hay una receta única y las decisiones deben ser tomadas en dependencia de los factores que las condicionan, tales como: la disponibilidad de recursos para el cultivo de la tierra y la siembra, las características del área donde se desarrollará el sistema, y las especies seleccionadas que puedan adaptarse totalmente a las condiciones edafoclimáticas. Sin embargo, se ha demostrado la superioridad de las asociaciones debido a una mayor ganancia diaria de peso vivo, una mayor disponibilidad de alimento, un notable incremento del nivel de proteína en las gramíneas asociadas, un mejor balance de nutrientes en el pasto y una mejor composición botánica (Tablas 1 y 2).

\section{EL USO DE LOS BANCOS DE PROTEÍNA PARA EL PASTOREO}

Pueden utilizarse diferentes alternativas de bancos de proteína para la producción de carne y leche en estos sistemas de pastoreo:

- Bancos de proteína en sistemas de pastoreo con gramíneas naturales.

- Bancos de proteína en sistemas de pastoreo con gramíneas cultivadas.

- Bancos de proteína con una leguminosa asociada a las gramíneas.

- Bancos de proteína de asociaciones múltiples de leguminosas con gramíneas.

Según Hernández y Simón, (1993) esta tecnología consiste en la siembra de árboles, arbustos y plantas herbáceas con un alto contenido de proteínas (generalmente leguminosas), en altas densidades en una determinada área de pastoreo. Ruiz y Febles, (1999) plantearon que el manejo de los bancos de proteína para el pastoreo es simple, y admite que un vaquero experimentado y 
cuidadoso lo realice con eficiencia. El área de las leguminosas debe dividirse en cuartones y rotarse, de manera tal que garantice períodos de descanso no menores que cinco semanas, que pudieran alargarse en el caso de que sea necesario propiciar un rebrote fuerte y abundante de las leguminosas.

Tabla 1. Ganancia de peso vivo (g/animal/día), oferta de materia seca y de proteína bruta ( $\mathrm{kg} / 100 \mathrm{~kg}$ de PV/día) en diferentes sistemas de pastoreo

\begin{tabular}{|c|c|c|c|}
\hline Indicador & Asociación* & Banco de proteína* & Guinea likoni** \\
\hline \multicolumn{4}{|c|}{ Ganancia de peso vivo (g/animal/día) } \\
\hline Ceba inicial (lluvia) & 820 & 760 & 800 \\
\hline Ceba final (seca) & 426 & 301 & 276 \\
\hline Promedio & 623 & 530 & 536 \\
\hline \multicolumn{4}{|c|}{ Oferta de materia seca (kg/100 kg de PV/día) } \\
\hline Ceba inicial (lluvia) & 20,7 & 15,7 & 16,6 \\
\hline Ceba final (seca) & 12,9 & 11,2 & 10,1 \\
\hline \multicolumn{4}{|c|}{ Oferta de proteína bruta (kg/100 kg de PV/día) } \\
\hline Ceba inicial (lluvia) & 3,18 & 1,26 & 1,42 \\
\hline Ceba final (seca) & 1,84 & 0,69 & 0,66 \\
\hline
\end{tabular}

* Leucaena, teramnus, glycine, siratro, indigofera y likoni

** Fertilizada con 80 kg N/ha/año

Fuente: Iglesias, (2003).

El manejo de las leguminosas puede ser igual al de las gramíneas cuando el banco es manejado con libre acceso, o diferenciado, controlando el acceso de los animales mediante el empleo de una cerca que separe el área del banco del resto del cuartón, en dependencia de sus características específicas.

El acceso libre de los animales es aconsejable en los casos en que el banco de proteína haya sido establecido sobre la base de pastos naturales, de forma tal que pueda ser explotado como un solo cuartón en pastoreo continuo, abriendo el portón del área de leguminosas cuando estas hayan alcanzado buen rebrote y biomasa, y cerrándolo cuando los animales lo hayan consumido convenientemente.

Cuando el banco de proteína ha sido sembrado en áreas de gramíneas cultivadas, fertilizadas o no, es aconsejable el pastoreo diferido, que consiste en dar acceso a 
éste sólo en el período de menos disponibilidad de pastos (noviembre a mayo). Esto facilita un período de descanso de alrededor de cuatro meses durante la estación lluviosa, especialmente para las leguminosas herbáceas y volubles, que pueden recuperarse y persistir en el tiempo.

Tabla 2. Desarrollo de novillos que pastorean en pastos naturales asociados con L. leucocephala o en bancos de proteína

\begin{tabular}{|c|c|c|c|c|}
\hline \multirow[b]{2}{*}{ Indicador } & \multicolumn{3}{|c|}{ Tratamientos } & \multirow[b]{2}{*}{ Significación } \\
\hline & $\begin{array}{c}\text { Control } \\
\text { (pasto } \\
\text { natural) }\end{array}$ & $\begin{array}{l}\text { Banco de proteína } \\
\text { ( } 30 \% \text { de leucaena) }\end{array}$ & $\begin{array}{c}\text { Asociación } \\
\text { (100\% de } \\
\text { leucaena) }\end{array}$ & \\
\hline \multicolumn{5}{|c|}{ Primavera (267 días) } \\
\hline Peso inicial $(\mathrm{kg})$ & 149 & 149 & 150 & NS \\
\hline Peso final (kg) & $263^{b}$ & $293^{a}$ & $299^{\mathrm{a}}$ & $\mathrm{P}<0,001$ \\
\hline Ganancia diaria de PV (g/día) & $412^{b}$ & $536^{\underline{a}}$ & $555^{\mathrm{a}}$ & $\mathrm{P}<0,001$ \\
\hline \multicolumn{5}{|c|}{ Sequía (118 días) } \\
\hline Peso inicial $(\mathrm{kg})$ & $263^{b}$ & $293^{\mathrm{a}}$ & $299 \mathrm{a}$ & $P<0,001$ \\
\hline Peso final (kg) & $312^{\mathrm{a}}$ & $357^{\mathrm{b}}$ & $384^{\circ}$ & $P<0,001$ \\
\hline Ganancia diaria de PV (g/día) & $415^{\mathrm{a}}$ & $542^{b}$ & $718^{c}$ & $\mathrm{P}<0,001$ \\
\hline \multicolumn{5}{|c|}{ Total (385 días) } \\
\hline Peso inicial (kg) & 149 & 149 & 150 & NS \\
\hline Peso final $(\mathrm{kg})$ & $312^{\mathrm{a}}$ & $357^{b}$ & $384^{c}$ & $P<0,001$ \\
\hline Ganancia diaria de PV (g/día) & $425^{\mathrm{a}}$ & $539^{b}$ & $605^{\circ}$ & $P<0,001$ \\
\hline Ganancia (kg/ha/año) & $310^{a}$ & $394^{\mathrm{b}}$ & $442^{\mathrm{c}}$ & $P<0,001$ \\
\hline $\begin{array}{l}\text { Consumo de caña de azúcar } \\
\text { (kg MV/animal/día) }\end{array}$ & $7,6^{\mathrm{a}}$ & $7,8^{\mathrm{a}}$ & $6,7^{\mathrm{b}}$ & $P<0,001$ \\
\hline
\end{tabular}

Fuente: Castillo et al,, (1998).

La proporción que deben tener los bancos de proteína en el sistema puede ser 50:50, 70:25 ó 70:30\% gramínea-banco de proteína, en dependencia del sistema de manejo escogido por el productor.

Cuando se utiliza el manejo diferido (el banco no es pastoreado en la estación lluviosa) y prevalecen los pastos naturales, se obtienen mejores resultados con 25-30\% ocupado por las leguminosas; sin embargo, si prevalecen las gramíneas cultivadas o el acceso es libre, mientras mayor sea la proporción de leguminosas 
mejores serán los resultados de producción. Si el área dedicada a las gramíneas no se fertiliza, la carga global no debe ser mayor que 2 animales/ha; con niveles de $100 \mathrm{~kg}$ de N/ha/año o más, esta puede aumentar a 3 animales/ha.

En general, se aprecia que los bancos de proteína surgen por la necesidad de ofrecer un suplemento de alto valor nutricional para los animales en pastoreo, aunque debe plantearse que se necesita un manejo diferido de las leguminosas, que asegure su persistencia a más largo plazo y al mismo tiempo permita manejar las gramíneas más intensivamente. El área dedicada a los bancos es muy diversa y varía desde 25 hasta $50 \%$, en dependencia del propósito productivo y las especies utilizadas.

En Cuba, con el uso de la leucaena, se han alcanzado producciones de leche en bancos de proteína de 9-10 L/vaca/día, cuando el área de las gramíneas ha sido fertilizada (Milera et al., 1994). Lamela et al., (1996a; 1996b) obtuvieron resultados similares. En estas condiciones de manejo y sin el uso de insumos externos, pueden esperarse ganancias diarias de $500 \mathrm{~g} / \mathrm{animal} / \mathrm{día}$ o más en sistemas de engorde en pastoreo, alcanzando un peso vivo final de alrededor de $400 \mathrm{~kg}$ con 24-26 meses de edad y producciones de 400-800 kg de carne/ha (Hernández et al., 1992; Febles et al., 1996; Castillo et al., 1989; Ruiz y Febles, 1999). En las Tablas 3 y 4 aparecen algunos resultados que demuestran las posibilidades reales de los bancos de proteína para la producción de carne.

La Tabla 5 ofrece los resultados productivos de un sistema de pastoreo utilizado para la crianza de novillas de tipo Cebú, en el que el sistema tradicional de crianza sobre la base de gramíneas nativas se sustituyó por un sistema de banco de proteína con L. leucocephala (2 300 árboles/ha) y Andropogon gayanus como una gramínea básica cultivada (Hernández, Carballo y Reyes, 1997). Se evaluaron tres ciclos consecutivos de crianza, con cargas entre 2 y 2,7 novillas/ha, en pastoreo rotacional en cuatro cuartones y acceso diario a la leucaena, lo que representó el $33 \%$ del área total del sistema de pastoreo. Los indicadores de producción fueron superiores a los obtenidos con los sistemas tradicionales, en los cuales la edad de incorporación a la reproducción sobrepasa los 30 meses. 
Tabla 3. Comportamiento de terneros castrados que pastorean en bancos de proteína de leucaena

\begin{tabular}{cccccccc}
\hline $\begin{array}{c}\text { Área de } \\
\text { Leucaena } \\
(\%)\end{array}$ & Gramínea & $\begin{array}{c}\text { Carga } \\
\text { (animales/ha) }\end{array}$ & $\begin{array}{c}\text { Alimento } \\
\text { adicional }\end{array}$ & $\begin{array}{c}\mathbf{N} \\
\text { (kg/ha/año) }\end{array}$ & $\begin{array}{c}\text { Ganancia } \\
\text { (g/animal/día) } \\
\mathbf{k g} / \mathbf{h a} / \text { año }\end{array}$ & $\begin{array}{c}\text { Número } \\
\mathbf{d e} \\
\text { cuartones }\end{array}$ \\
\hline 30 & Guinea & 2 & - & - & $(538)$ & 392 & 4 \\
30 & Estrella & 3 & - & - & $(465)$ & 509 & 4 \\
30 & Estrella & 3 & - & 90 & $(532)$ & 583 & 4 \\
30 & Estrella & 5 & - & - & $(380)$ & 465 & 24 \\
30 & Natural & 2 & Caña & - & $(371)$ & 271 & 4 \\
50 & Guinea & 2 & con urea & - & $(556)$ & 406 & 4 \\
\hline
\end{tabular}

Fuente: Adaptado de Castillo et al., (1998).

Tabla 4. Resultados con leucaena y neonotonia como banco de proteína en suelo Ferralítico Amarillo lixiviado y con precipitación de 800-900 mm/año

\begin{tabular}{lcccc}
\hline \multicolumn{1}{c}{ Sistema de pastoreo } & $\begin{array}{c}\text { Carga } \\
\text { (animales/ha) }\end{array}$ & $\begin{array}{c}\text { Ganancia } \\
\text { diaria } \\
\text { (g/animal) }\end{array}$ & $\begin{array}{c}\text { Peso final } \\
\text { al sacrificio } \\
\text { (kg) }\end{array}$ & $\begin{array}{c}\text { Edad al } \\
\text { sacrificio } \\
\text { (meses) }\end{array}$ \\
\hline $\begin{array}{l}\text { A. gayanus + banco de proteína } \\
\text { de leucaena y neonotonia }\end{array}$ & 1,7 & 487 & 449 & 29 \\
$\begin{array}{l}\text { Pasto natural + banco de proteína } \\
\text { de leucaena y neonotonia }\end{array}$ & 1,7 & 394 & 355 & 24 \\
\hline
\end{tabular}

Nota: Sin suplementación

Fuente: Hernández et al., (1992)

Por otra parte, Iglesias, (2003) estudió el comportamiento de novillas $3 / 4$ Holstein $x$ $1 / 4$ Cebú en un sistema de banco de proteína de leucaena y otras leguminosas herbáceas (25\% del área total de pastoreo) con guinea likoni en el $75 \%$ del área, con una carga de 2,5 terneras/ha, y obtuvo un peso de incorporación a la reproducción de $292,3 \mathrm{~kg}$ con 26,5 meses de edad. Estos resultados se corresponden con una tasa de crecimiento de 449,1 g/animal/día, aunque es importante destacar que los animales fueron incorporados al pastoreo con un peso corporal muy bajo (sólo $100 \mathrm{~kg}$ ), lo que indica que las ganancias diarias en el período posparto hasta un año de edad no fueron superiores a $120 \mathrm{~g} / \mathrm{animal}$, con consecuencias para la edad de incorporación a la reproducción. 
Tabla 5. Comportamiento de novillas en crecimiento para reemplazo en un sistema de banco de proteína con A. gayanus y L. leucocephala

\begin{tabular}{lccc}
\hline \multirow{2}{*}{ Indicador } & \multicolumn{3}{c}{ Período } \\
\cline { 2 - 4 } & I & II & III \\
\hline Edad inicial (meses) & 15 & 16 & 12 \\
Peso inicial (kg) & 191,3 & 171,4 & 156,1 \\
Ganancia acumulada (g/animal/día) & 407 & 348,8 & 300 \\
Peso de incorporación a la reproducción (kg) & 285,3 & 281 & 276 \\
Edad de incorporación a la reproducción (meses) & 22 & 27 & 25 \\
Eficiencia reproductiva (asumiendo un estándar de 18 & 77,7 & 50 & 61,1 \\
meses con 280 kg de PV como el 100\%) & & & \\
\hline
\end{tabular}

Ruiz et al., (1990) recomendaron criar hembras en crecimiento mediante el empleo de bancos de proteína de acceso libre y limitado y suplementación con concentrados en la estación seca. En estos sistemas los animales deben incorporarse a la reproducción con una edad de 19 meses, un peso vivo de $324 \mathrm{~kg}$ y ganancias acumuladas de $634 \mathrm{~g} /$ animal/día. También sugirieron que, en el caso de no utilizar riego ni fertilización, se ofrezcan forrajes voluminosos adicionales durante la sequía.

Si se desea que los animales ganen más peso (más de 600 g/día), se aconseja el suministro de $2 \mathrm{~kg}$ de suplemento por día, lo que representa un ahorro de $450 \mathrm{~kg}$ de alimento concentrado por animal. Según estos autores, para obtener una ganancia diaria de $500 \mathrm{~g}$ no es necesaria la suplementación (Tabla 6).

Los mejores resultados en la producción de leche con la tecnología del banco de proteína se han alcanzado cuando el área del banco representa el 20-25\% del área total de pastoreo, con acceso limitado de los animales y un tiempo de pastoreo entre dos y cuatro horas al día.

Para facilitar el manejo, el banco de proteína debe estar tan cercano como sea posible al edificio de ordeño y las otras instalaciones de la vaquería. El área se divide, al menos, en cuatro cuartones para garantizar el pastoreo rotacional y el reposo de las leguminosas. En la Tabla 7 se exponen algunos resultados en cuanto a la producción de leche utilizando bancos de proteína de L. leucocephala. 
Tabla 6. Principales indicadores en la cría de novillas de reemplazo con la tecnología de banco de proteína

\begin{tabular}{ccccccc}
\hline $\begin{array}{c}\text { Tipo de } \\
\text { animal }\end{array}$ & $\begin{array}{c}\text { Edad o } \\
\text { peso }\end{array}$ & $\begin{array}{c}\text { Carga } \\
\text { (animales/ha) }\end{array}$ & $\begin{array}{c}\text { Aplicación } \\
\text { de N }\end{array}$ & Acceso & Área & $\begin{array}{c}\text { Cuando } \\
\text { suplementar }\end{array}$ \\
\hline Ternera & $\begin{array}{c}10-12 \\
\text { meses }\end{array}$ & 4 & Sí & Libre & $30-50 \%$ & $\begin{array}{c}\text { A partir de } \\
600 \\
\text { g/animal/día } \\
150-200 \mathrm{~kg}\end{array}$ \\
Novilla & - & $3-3,5$ & Sí & Limitado & $25-30 \%$ & $\begin{array}{c}400 \mathrm{~kg} \\
\text { PV/novilla }\end{array}$ \\
\hline
\end{tabular}

Fuente: Adaptado de Ruiz et al., (1990)

Tabla 7. Producción de leche utilizando bancos de proteína de leucaena

\begin{tabular}{lcccc}
\hline Especie utilizada & $\begin{array}{c}\text { Carga } \\
\text { (vacas/ha) }\end{array}$ & $\begin{array}{c}\text { Nivel de N } \\
\text { (kg/ha/año) }\end{array}$ & $\begin{array}{c}\text { Producción } \\
\text { (kg/vaca/día) }\end{array}$ & Autor \\
\hline Likoni + leucaena & 2,5 & 140 & 10,1 & Milera et al., (1994) \\
$\begin{array}{l}\text { Likoni + leucaena }+ \\
\text { glycine }\end{array}$ & 2,5 & 80 & $9,3^{* *}$ & Lamela y Matías (1989) \\
$\begin{array}{l}\text { Pasto estrella }+ \\
\text { leucaena }\end{array}$ & 2,0 & 0 & $5,7^{* *}$ & Lamela et al., (1996a) \\
$\begin{array}{l}\text { Likoni + leucaena } \\
\begin{array}{l}\text { Pasto estrella }+ \\
\text { likoni + leucaena }\end{array}\end{array}$ & 2,0 & 0 & $6,7^{* *}$ & Lamela et al., (1996b) \\
\hline
\end{tabular}

\section{EL USO DE ASOCIACIONES DE GRAMÍNEAS Y LEGUMINOSAS}

Actualmente hay una mayor claridad acerca del procedimiento para alcanzar el éxito esperado de esos sistemas, aunque aún hay mucho que hacer para optimizar su uso y explotación. La clave del éxito es lograr una asociación múltiple, bien establecida, de leguminosas y gramíneas de diferente comportamiento estacional y hábitos de crecimiento trepador, rastrero, arbustivo y arbóreo, que conformen una comunidad vegetal caracterizada por una amplia diversidad de especies, donde los árboles y/o arbustos proyecten una sombra difusa sobre la superficie del suelo y las gramíneas acompañantes.

Este sistema favorece su propia nutrición y sostenibilidad a través de la fijación del nitrógeno atmosférico, la extracción (de los horizontes más profundos del suelo) de otros minerales mediante las raíces de los árboles y la deposición de las hojas 
muertas y las excretas de los animales en la superficie del suelo, lo que se manifiesta estacionalmente en la alta y estable disponibilidad de biomasa de MS y en la evolución positiva del suelo.

Por otra parte, la atmósfera boscosa facilita la retención de humedad, aumenta la actividad biológica del suelo a través de la biota edáfica y crea un hábitat que estimula la presencia de otras especies de la fauna, lo que favorece el mantenimiento de un balance ecológico y la protección del medio ambiente.

El balance leguminosas-gramíneas es favorecido, aparentemente, por la sombra difusa que proporcionan los árboles y los arbustos, lo que contribuye al desarrollo de las leguminosas trepadoras y rastreras y suaviza la agresividad de las gramíneas, retardando su proceso natural de maduración. Las ramas leñosas de los árboles y los arbustos sirven como tutores para las leguminosas que trepan hasta las partes superiores de los árboles, donde producen abundante biomasa y no pueden ser alcanzadas por los animales. Esto les permite continuar el proceso de fotosíntesis y, por tanto, la acumulación de reservas que garantizan el futuro rebrote de las partes devoradas. En este estrato superior puede producirse una cantidad importante de semillas, que caen al suelo estacionalmente y crean un almacenamiento natural que garantiza la persistencia y la estabilidad del sistema. La especie arbórea más estudiada y utilizada en Cuba es L. leucocephala, una planta muy apetitosa cuyo consumo puede controlarse, permitiéndole que crezca para que los animales no puedan ramonear todo el follaje disponible y este puede cosecharse posteriormente mediante la poda. Esta particularidad lo protege de las altas cargas, porque el tallo y las ramas no son dañados en exceso y el follaje residual es suficiente para continuar la fotosíntesis de forma eficiente, garantizando un buen rebrote en un período aproximado de cinco a nueve semanas. Se destaca por su valor nutricional, que puede ser similar a una proteína concentrada de alta calidad, como la caseína protegida, cuando se suministra en niveles de 2 a $4 \mathrm{~kg}$ de materia verde por vaca por día; también sobresale por sus amplias posibilidades de utilizar la humedad del suelo y sus nutrientes, lo que 
favorece la producción de biomasa en condiciones de tierra seca. Puede fijar más de $200 \mathrm{~kg}$ de N/ha/año.

Entre las leguminosas trepadoras se destacan Neonotonia wightii cv. Tinaroo, Teramnus labialis cv. Semilla clara, Centrosema pubescens cv. SIH-129 y Macroptilium atropurpureum cv. Siratro. Ellas actúan como un complemento valioso de la dieta y también fijan el nitrógeno atmosférico. Su comportamiento estacional individual tiene una gran influencia en la estabilidad del balance de leguminosas-gramíneas y su hábito trepador las protege del daño excesivo por parte de los animales.

La gramínea cultivada Panicum maximum (cualquiera de las variedades comerciales o una mezcla de ellas) presenta rangos estrechos de variación de la digestibilidad de MS que permiten ciclos amplios de rotación; sus rendimientos son menos afectados por la sequía y tiene un buen comportamiento bajo la sombra difusa de los árboles.

El manejo de las asociaciones debe ser flexible y las variaciones en la intensificación de la explotación deben hacerse según la producción total de biomasa, y en particular cuando la disponibilidad de las gramíneas aumenta 0 disminuye. En este sentido, cuando ocurren los picos de producción de MS (durante la estación lluviosa) el nivel de explotación debe incrementarse mediante la reducción del ciclo de rotación. Este último debe ser más amplio cuando la producción de MS cae a niveles bajos (período seco). De esta forma, las cargas varían estacionalmente sin necesidad de sacar los animales de los pastos. La magnitud del ciclo de rotación se define por el grado de recuperación del pastizal después del pastoreo, el cual varía en función de la intensidad de defoliación.

Estos sistemas silvopastoriles tienen un potencial de producción de alrededor de 7-8 kg de leche/vaca/día sin utilizar suplementos energético-proteicos. La Tabla 8 muestra algunos de estos resultados.

La introducción de esta tecnología de asociación de árboles en toda el área de pastoreo, conocida popularmente como silvopastoreo, comenzó en 1995 y ha 
tenido un buen desarrollo en diferentes provincias de Cuba. La tecnología ha demostrado, en condiciones comerciales, sus potencialidades para elevar los indicadores productivos y reproductivos del ganado criado en este sistema. Se han obtenido rendimientos lecheros de hasta $3000 \mathrm{~kg} / \mathrm{ha} / \mathrm{año}$ y más de 2800 $\mathrm{kg} / \mathrm{lactancia}$. También puede alcanzarse un peso vivo entre 600 y $800 \mathrm{~kg} / \mathrm{ha} / \mathrm{año}$, al igual que mejoras reproductivas, como la tasa de parición de $80 \%$, el intervalo de parto de 403 días como promedio y $69 \%$ de vacas en ordeño (Tabla 9 ).

Tabla 8. Algunos resultados productivos de un sistema silvopastoril multiasociado

\begin{tabular}{|c|c|c|c|c|c|c|}
\hline $\begin{array}{c}\text { Condiciones } \\
\text { experimentales }\end{array}$ & $\begin{array}{l}\text { Rendimiento } \\
\text { (t/ha/rotación) }\end{array}$ & $\begin{array}{c}\text { Carga } \\
\text { global } \\
\text { (vacas } / \text { ha) }\end{array}$ & $\begin{array}{c}\text { Intensidad } \\
\text { de pastoreo } \\
\text { (vacas/ha/día) }\end{array}$ & $\begin{array}{c}\text { Oferta de } \\
\text { MS } \\
\text { (kg/vaca/día) }\end{array}$ & $\begin{array}{l}\text { PB } \\
(\%)\end{array}$ & $\begin{array}{l}\text { Leche } \\
\text { (kg/día) }\end{array}$ \\
\hline \multicolumn{7}{|c|}{ Período poco lluvioso } \\
\hline $\begin{array}{l}\text { A) Alta } \\
\text { intensidad } \\
\text { de explotación }\end{array}$ & 4,5 & 2,8 & 177,3 & 24,6 & 15,2 & $\begin{array}{l}8,4 \\
6,8^{*}\end{array}$ \\
\hline $\begin{array}{l}\text { B) Intensidad } \\
\text { de explotación } \\
\text { media }\end{array}$ & 4,7 & 1,7 & 106,4 & 42,2 & 15,2 & $\begin{array}{l}8,7 \\
7,2^{*}\end{array}$ \\
\hline $\begin{array}{l}\text { C) Baja } \\
\text { intensidad } \\
\text { de explotación }\end{array}$ & 4,9 & 1,1 & 70,9 & 64,9 & 15,0 & $\begin{array}{l}8,1 \\
7,5^{\star}\end{array}$ \\
\hline $\mathrm{ES}( \pm)$ & 0,6 & & & - & 0,2 & $\begin{array}{l}0,3 \\
0,4^{*}\end{array}$ \\
\hline \multicolumn{7}{|c|}{ Período lluvioso } \\
\hline A & 7,1 & 4,7 & 206,0 & 26,6 & 15,3 & $\begin{array}{l}9,0 \\
6,5^{\star}\end{array}$ \\
\hline B & 7,2 & 2,8 & 159,6 & 44,8 & 14,4 & $\begin{array}{l}8,5 \\
6,6^{*}\end{array}$ \\
\hline C & 7,1 & 1,9 & 106,4 & 67,2 & 14,6 & $\begin{array}{l}8,9 \\
7,3^{*}\end{array}$ \\
\hline $\mathrm{ES}( \pm)$ & 0,3 & & & & 0,6 & $\begin{array}{l}0,3 \\
0,3^{*}\end{array}$ \\
\hline
\end{tabular}

${ }^{*}$ Con terneros en amamantamiento.

Fuente: Hernández et al., (1998).

Se han estudiado otros sistemas asociados de pastoreo, con buenos resultados en la producción de carne y la cría de novillas, sin el uso de fertilizantes ni suplementos. En un estudio realizado por Hernández, (2000) se evaluó el 
comportamiento de toros Cebú en cuatro sistemas de pastoreo con árboles y sin ellos, donde la gramínea básica fue la guinea likoni y los árboles asociados fueron L. leucocephala, Bauhinia purpurea y Albizia lebbeck. Se empleó una carga de 3 animales/ha y no hubo ninguna fuente de suplementación, excepto agua y sales minerales (Tabla10).

Tabla 9. Comportamiento productivo de seis vaquerías con la tecnología del silvopastoreo

\begin{tabular}{ccccccc}
\hline Vaquería & $\begin{array}{c}\text { Número } \\
\text { total } \\
\text { de vacas }\end{array}$ & $\begin{array}{c}\text { Vacas en } \\
\text { ordeño }\end{array}$ & $\%$ & $\begin{array}{c}\text { Producción } \\
\text { individual } \\
\text { (kg/vaca/día) }\end{array}$ & $\begin{array}{c}\text { Carga } \\
\text { (vacas/ha) }\end{array}$ & $\begin{array}{c}\text { Producción } \\
\text { por } \\
\text { hectárea }\end{array}$ \\
\hline 1 & 73 & 41 & 56 & 8,1 & 2,1 & 9,5 \\
2 & 78 & 45 & 58 & 9,2 & 2,6 & 13,8 \\
3 & 87 & 60 & 69 & 6,2 & 2,0 & 8,5 \\
4 & 86 & 67 & 66 & 5,8 & 2,0 & 7,6 \\
5 & 23 & 15 & 65 & 7,3 & 1,7 & 8,1 \\
6 & 32 & 22 & 68 & 8,0 & 2,0 & 10,9 \\
Total & 379 & 250 & - & - & - & - \\
X & - & 41,6 & 66 & 7,4 & 2,1 & 9,7 \\
\hline
\end{tabular}

Tabla 10. Productividad de animales Cebú en crecimiento que pastoreaban en sistemas de pastos con árboles asociados y sin estos

\begin{tabular}{lcccc}
\hline Sistema de pastoreo & $\begin{array}{c}\text { PV inicial } \\
\text { (kg/animal) }\end{array}$ & $\begin{array}{c}\text { PV Final } \\
\text { (kg/animal) }\end{array}$ & $\begin{array}{c}\text { Ganancia } \\
\text { de peso bruto } \\
\text { (kg/animal) }\end{array}$ & $\begin{array}{c}\text { Ganancia de } \\
\text { PV acumulada } \\
\text { (g/animal/día) }\end{array}$ \\
\hline $\begin{array}{l}\text { Leucaena asociada con } \\
\text { guinea }\end{array}$ & 226,9 & 424,0 & 197,1 & 788 \\
$\begin{array}{l}\text { Bauhinia asociada con } \\
\text { guinea }\end{array}$ & 226,3 & 415,5 & 189,1 & 757 \\
$\begin{array}{l}\text { Albizia asociada con } \\
\text { guinea } \\
\text { Guinea sola (fertilizada) }\end{array}$ & 227,0 & 409,2 & 182,2 & 729 \\
\hline
\end{tabular}

Fuente: Hernández, (2000).

Los resultados del comportamiento animal demostraron la superioridad de los sistemas asociados en comparación con el sistema de fertilizado tradicional, sin diferencias entre ellos en la tasa de crecimiento. Es importante reconocer que la inclusión de otras plantas arbóreas, como $A$. lebbeck y B. purpurea, evidenció su 
alta potencialidad para ser utilizadas como alimento para el ganado en sistemas con bajos insumos externos.

Por otra parte, Iglesias, (2003) evaluó la potencialidad de un sistema silvopastoril para la producción de carne utilizando terneros castrados provenientes de rebaños lecheros, que se alimentan tradicionalmente de forma intensiva. En un sistema de pastoreo compuesto por guinea likoni, Brachiaria decumbens cv. Basilisk y gramíneas naturales (Dichantium spp. y Paspalum notatum), asociadas a leucaena sembrada con una densidad de 555 árboles por hectárea, se demostró que aunque los animales cruzados no alcanzaron un peso de sacrificio similar a los del tipo Cebú, las ganancias diarias durante el período de ceba fueron suficientes para obtener animales de segunda categoría, con un peso final de alrededor de $355 \mathrm{~kg}$ y sin pérdidas económicas para el sistema (Tabla 11).

Con respecto a los sistemas de pastoreo para la crianza de novillas de reemplazo, también las asociaciones han corroborado la influencia de las leguminosas arbóreas en el comportamiento animal durante las diferentes etapas fisiológicas de estos animales jóvenes.

Iglesias (2003) logró un peso de incorporación a la reproducción de $310 \mathrm{~kg}$ en hembras mestizas 3/4 Holstein $\times 1 / 4$ Cebú que pastorearon en L. leucocephala (555 árboles/ha) asociada con guinea cv. Likoni y otras leguminosas herbáceas perennes ( $N$. wightii, M. atropurpureum, Indigofera mucronata, etc.). Las ganancias de peso vivo acumuladas (488 g/animal/día) fueron aceptables, pero la edad a la incorporación estuvo por encima de los indicadores deseados para una cría intensiva de ganado (27,4 meses).

Este mismo autor, al comparar hembras de diferentes razas en un sistema de guinea combinada con diferentes variedades de leucaena (Cunningham, Perú y CNIA-250), observó una reducción considerable en la edad de incorporación a la reproducción (22,8 meses) y ganancias de peso moderadas, apropiadas para el buen desarrollo de las futuras vacas lecheras (Tabla 12). 
Por otra parte, Mejías et al., (2000) diseñaron un sistema de cría de hembras donde primero se utilizó la leguminosa rastrera Stylosanthes guianensis asociada con gramíneas para destetar las terneras y posteriormente se introdujeron los animales en las áreas de pastos combinadas con leucacena. Las ganancias diarias fueron superiores a $500 \mathrm{~g}$, con una edad de incorporación a la reproducción de 22,3 meses y preñez de alrededor de 24 meses. El peso vivo en la incorporación también mostró un valor apropiado (304,5 kg).

Tabla 11. Comportamiento productivo de diferentes genotipos de toros según la estación

\begin{tabular}{|c|c|c|c|c|}
\hline Genotipo & $\begin{array}{c}\text { Peso inicial } \\
(\mathrm{kg})\end{array}$ & $\begin{array}{c}\text { Peso final } \\
(\mathrm{kg})\end{array}$ & $\begin{array}{l}\text { Ganancia } \\
\text { diaria (g) }\end{array}$ & $\begin{array}{c}\text { Edad } \\
\text { (meses) }\end{array}$ \\
\hline & Ceba inicial & Período lluvioso & & \\
\hline Cebú & 111,5 & $273,4^{\mathrm{a}}$ & $899^{a}$ & $12-18$ \\
\hline (1/2 Holstein x 1/2 Cebú) & 120,0 & $235,1^{b}$ & $639^{b}$ & \\
\hline ( $5 / 8$ Holstein $x 3 / 8$ cebú) & 117,1 & $233,0^{b}$ & $643^{b}$ & \\
\hline \multirow[t]{2}{*}{$\mathrm{ES} \pm$} & 3,1 & $8,4^{\star \star \star}$ & $29,7^{\star \star \star}$ & \\
\hline & Ceba final & Período poco lluv & vioso & \\
\hline Cebú & $273,0^{\mathrm{a}}$ & $315,5^{\mathbf{a}}$ & $236^{\underline{a}}$ & $18-24$ \\
\hline (1/2 Holstein x 1/2 Cebú) & $235,1^{b}$ & $283,5^{\mathrm{b}}$ & $268^{\mathrm{a}}$ & \\
\hline ( $5 / 8$ Holstein $\times 3 / 8$ cebú) & $233,0^{\mathrm{b}}$ & $264,8^{c}$ & $176^{\mathrm{b}}$ & \\
\hline \multirow[t]{2}{*}{$\mathrm{ES} \pm$} & $8,4^{\star \star *}$ & $5,3^{\star * *}$ & $16,4^{* * *}$ & \\
\hline & Ceba final & Período lluvioso & & \\
\hline Cebú & $315,5^{\mathrm{a}}$ & $413,7^{\mathrm{a}}$ & 785 & $24-28$ \\
\hline (1/2 Holstein x 1/2 Cebú) & $283,5^{b}$ & $376,3^{b}$ & 742 & \\
\hline ( $5 / 8$ Holstein $x 3 / 8$ cebú) & $264,8^{c}$ & $357,1^{\mathrm{c}}$ & 738 & \\
\hline$E S \pm$ & $5,3^{\star \star \star *}$ & $9,9^{*}$ & 16,3 & \\
\hline \multicolumn{5}{|c|}{ Promedio acumulado durante todo el período de ceba } \\
\hline Cebú & 111,5 & $413,7^{\mathrm{a}}$ & $621,8^{\mathrm{a}}$ & 16 \\
\hline (1/2 Holstein $\times 1 / 2$ Cebú) & 120,0 & $376,3^{b}$ & $525,6^{b}$ & \\
\hline ( $5 / 8$ Holstein $x$ 3/8 cebú) & 117,1 & $357,1^{c}$ & $491,6^{b}$ & \\
\hline$E S \pm$ & 3,1 & $9,9^{*}$ & $11,5^{\star}$ & \\
\hline
\end{tabular}

a,b,c Valores con superíndices diferentes en la misma columna difieren a $\mathrm{P}<0,05$ (Duncan, 1955)

${ }^{*} \mathrm{P}<0,05 \quad{ }^{* *} \mathrm{P}<0,01 \quad{ }^{* * *} \mathrm{P}<0,001$

La sustitución de alimento concentrado para esta categoría es posible si se tienen en cuenta los resultados de Zarragoitía et al., (1992); estos autores compararon el 
sistema de pastoreo tradicional de bermuda cv. 68, fertilizada y con suplemento de concentrados, con el uso de esta gramínea asociada a la leucaena y no encontraron diferencias en las ganancias de peso diarias (569 vs 530 g/animal/día) y en la edad (18 vs 19,3 meses) y el peso vivo (323 vs $321 \mathrm{~kg}$ ) de incorporación, lo que demuestra el potencial de la asociación desde el punto de vista productivo y económico, por ahorrar concentrado y fertilizante.

Tabla 12. Comportamiento de hembras de diferentes razas en pastoreo

\begin{tabular}{|c|c|c|c|}
\hline \multirow[b]{2}{*}{ Indicador } & \multicolumn{2}{|c|}{ Tipo de animal } & \multirow[b]{2}{*}{ ES \pm} \\
\hline & $\begin{array}{c}F_{1}(1 / 2 \text { Holstein } \\
\text { X } 1 / 2 \text { Cebú })\end{array}$ & $\begin{array}{c}5 / 8 \text { Holstein } \times 3 / 8 \\
\text { Cebú }\end{array}$ & \\
\hline Peso vivo inicial (kg) & 164,2 & 170,9 & 2,47 \\
\hline Peso vivo final $(\mathrm{kg})$ & 294,9 & 280,8 & $3,67^{\star}$ \\
\hline Edad de incorporación (meses) & 22,7 & 22,8 & 1,05 \\
\hline $\begin{array}{l}\text { Ganancia promedio acumulada } \\
\text { (g/animal/día) }\end{array}$ & 524,5 & 440,8 & $20,08^{* *}$ \\
\hline $\begin{array}{l}\text { Ganancia promedio durante el } \\
\text { período seco (g/animal/día) }\end{array}$ & 508,6 & 421,0 & $18,68^{\star *}$ \\
\hline $\begin{array}{l}\text { Ganancia promedio durante el } \\
\text { período lluvioso (g/animal/día) }\end{array}$ & 584,6 & 495,0 & $18,08^{* *}$ \\
\hline
\end{tabular}

\section{CONCLUSIONES}

Los estudios realizados y los resultados productivos obtenidos hasta el momento demuestran que los sistemas silvopastoriles constituyen una alternativa de valor que pudiera tener un papel importante en la recuperación de la producción ganadera tropical, y en particular, de leche y carne, dos de los alimentos más importantes para satisfacer las necesidades de la población.

\section{REFERENCIAS BIBLIOGRÁFICAS}

1. Castillo, E.; Ruiz, T.; Crespo, G.; Galindo, J.; Chongo, B.; Hernández, J. L. Efecto de la suplementación con caña/urea en machos bovinos que pastan en áreas de pastos naturales asociados totalmente con leucaena. Memorias. III Taller Internacional Silvopastoril "Los árboles y arbustos en la ganadería". EEPF "Indio Hatuey". Matanzas, Cuba. 1998: 232. 
2. Castillo, E.; Ruiz, T.E.; Puentes, R.; Lucas, E. Producción de carne bovina en área marginal con guinea (Panicum maximum Jacq.) y leucaena (Leucaena leucocephala). I. Comportamiento animal. Rev. cubana Cienc. agríc. 1989: 23:137.

3. Chao, La; Valdés, L.R., Duquesne, P. Uso de las leguminosas o suplementación para la producción de carne. II. Ciclo de evaluación. Pastos y Forrajes. 1982: 5:223.

4. Delgado, A.; García-Trujillo, R.; Molina, A.; Elías, A.; Reyes, J.; Sardiñas, O.; Hernández, $\mathrm{H}$. Efecto del formaldehído asperjado en la harina de girasol para bovinos en crecimientoceba alimentados con miel-urea. Rev. cubana Cienc. agríc 1994:28:181.

5. Febles, G.; Ruiz, T.E.; Simón, L. Consideraciones acerca de la integración de los sistemas silvopastoriles a la ganadería tropical y subtropical. En: Leguminosas forrajeras arbóreas en la agricultura tropical. (Ed. T. Clavero). Centro de Transferencia de Tecnología en Pastos y Forrajes. La Universidad del Zulia, Venezuela. 1996: 91.

6. Hernández, C.A.; Alfonso, A.; Duquesne, P. Producción de carne basada en pastos naturales mejorados con leguminosas arbustivas y herbáceas. I. Ceba inicial. Pastos y Forrajes. 1986: 9:79.

7. Hernández, C.A.; Alfonso, A.; Duquesne, P. Producción de carne basada en pastos naturales mejorados con leguminosas arbustivas y herbáceas. II. Ceba final. Pastos y Forrajes. 1987:10:245

8. Hernández, C.A.; Alfonso, A.; Duquesne, P. Banco de proteína de Neonotonia wightii y Macroptilium atropurpureum como complemento al pasto natural en la ceba de bovinos. Pastos y Forrajes. 1988:11:74

9. Hernández, D.; Carballo, M.; Reyes, F. Desarrollo de hembras de cría a base de pastos. Pastos y Forrajes. 1997: 20:175

10. Hernández, D.; Carballo, M.; Reyes, F. Sistema silvopastoril multiasociado: una alternativa para la producción de leche y carne en Cuba. EEPF "Indio Hatuey". Matanzas. Cuba. 1998:14 p.

11. Hernández, D.; Hernández, I.; Hernández, C.A.; Carballo, M.; Carnet, R.; Mendoza, R.; Mendoza, C.; Rodríguez, N. Ceba de bovinos con Andropogon gayanus CIAT-621 complementado con un banco de proteína de Leucaena leucocephala y Neonotonia wightii. Pastos y Forrajes. 1992:15:153

12. Hernández, I. Utilización de las leguminosas arbóreas L. leucocephala, A. lebbeck y $B$. purpurea en sistemas silvopastoriles. Tesis presentada en opción al grado científico de Dr. en Ciencias Agrícolas. ICA. La Habana, Cuba. 2000: 138.

13. Hernández, I.; Simón, L. Los sistemas silvopastoriles: empleo de la agroforestería en las explotaciones ganaderas. Pastos y Forrajes. 1993:16:99. 
14. Iglesias, J.M. La utilización de la Leucaena leucocephala en un contexto silvopastoril para la producción bovina. Tesis presentada en opción al título de Master en Pastos y Forrajes. EEPF "Indio Hatuey". Matanzas, Cuba.1996.

15. Iglesias, J.M. Los sistemas silvopastoriles, una alternativa para la crianza de bovinos jóvenes en condiciones de bajos insumos. Tesis presentada en opción al grado de Dr. en Ciencias Veterinarias. Instituto de Ciencia Animal. La Habana, Cuba. 2003: 110.

16. Lamela, L.; Matías, C. Tecnología integral de manejo y alimentación con la hierba guinea en condiciones de secano. Informe del programa de tecnología integral para la producción de leche y carne. EEPF "Indio Hatuey". Matanzas, Cuba. (Mimeo) 1989.

17. Lamela, L.; Matías, C.; Fung, C.; Valdés, R. Efecto del banco de proteína en la producción de leche. Memorias. III Taller Internacional Silvopastoril "Los Árboles y arbustos en la ganadería”. EEPF "Indio Hatuey". Matanzas, Cuba. 1998: 228.

18. Lamela, L.; Valdés, R.; Fung, C. Comportamiento del banco de proteína para la producción de leche. Resúmenes. X Seminario Científico de Pastos y Forrajes. EEPF "Indio Hatuey", Matanzas, Cuba. p. 14

19. Lamela, L.; Valdés, L.R.; Fung, C. 1996b. Producción de leche en un sistema con banco de proteína. Resúmenes. Taller Internacional "Los árboles en los sistemas de producción ganadera". EEPF "Indio Hatuey". Matanzas, Cuba. 1966: 77.

20. López, O. Caracterización del comportamiento productivo y reproductivo de vacas Mambí de primera lactancia en un sistema silvopastoril. Tesis presentada en opción al Título Académico de Master en Reproducción Animal. Centro Nacional de Sanidad Agropecuaria. Universidad Agraria de La Habana, Cuba. 2004: 115.

21. Mejías, R.; Ruiz, T.E.; López, M.A. Evaluación del crecimiento y la reproducción de novillas lecheras en pastoreo de leguminosa. Resúmenes. I Congreso Internacional sobre Mejoramiento Animal. Palacio de las Convenciones de La Habana, Cuba. 2000: 132.

22. Milera, M.; Iglesias, J.M.; Remy, V.; Cabrera, N. Empleo del banco de proteína de Leucaena leucocephala cv. Perú para la producción de leche. Pastos y Forrajes. 1994:17:73.

23. Preston, T.R. Tropical animal feeding. A manual for research workers. FAO Animal production and health paper No. 126. Roma. 1995:305.

24. Reinoso, M. Contribución al conocimiento del potencial lechero y reproductivo de sistemas de pastoreo arborizados empleando vacas Siboney de Cuba. Tesis presentada en opción al grado científico de Doctor en Ciencias Veterinarias. Universidad Central “Marta Abreu”. Santa Clara, Cuba. 2000:99. 
25. Ruiz, T.E.; Febles, G. Sistemas silvopastoriles. Conceptos y tecnologías desarrolladas en el Instituto de Ciencia Animal. (Eds. T.E. Ruiz \& G. Febles). EDICA. La Habana, Cuba. 1999:33.

26. Ruiz, T.E.; Febles, G.; Jordán, H.; Castillo, E.; Galindo, J. Sistemas silvopastoriles. Análisis conceptual de las investigaciones. Memorias. IV Taller Internacional Silvopastoril "Los árboles y arbustos en la ganadería tropical". EEPF "Indio Hatuey". Matanzas, Cuba. Tomo II, 2000: 499.

27. Ruiz, T.E.; Febles, G.; Sistachs, M.; Bernal, G.; León J.J. Prácticas para el control de malezas durante el establecimiento de Leucaena leucocephala en Cuba. Rev. cubana Cienc. agríc. 1990:24:241.

28. Sánchez T. Evaluación de un sistema silvopastoril con hembras Mambí de primera lactancia bajo condiciones comerciales. Tesis presentada en opción al grado científico de Master en Pastos y Forraje. Universidad de Camilo Cienfuegos, Matanzas, 2000: 93.

29. Simón, L. Rol de los árboles y arbustos multipropósitos en las fincas ganaderas. En: Leguminosas forrajeras arbóreas en la agricultura tropical. (Ed. T. Clavero). Centro de Transferencia de Tecnología en Pastos y Forrajes. La Universidad del Zulia, Venezuela. 1996: 41.

30. Simón, L.; Iglesias, J.M.; Hernández, C.A.; Hernández, I.; Duquesne, P. 1990. Producción de carne a base de pastoreo combinado de gramíneas y leguminosas. Pastos y Forrajes. 13:179.

31. Simón, L.; Francisco, A.G. Potencialidades productivas del silvopastoreo. Memorias IV Taller Internacional Silvopastoril "Los árboles y arbustos en la ganadería tropical". EEPF "Indio Hatuey". Matanzas, CubaTomo II, . 2000: 467

32. Simón, L. Impacto bioeconómico y ambiental de la tecnología del silvopastoreo racional en Cuba. En: Silvopastoreo: un nuevo concepto del pastizal. (Ed. L. Simón). EEPF "Indio Hatuey". Matanzas, Cuba. 2005: 203.

33. Zarragoitía, L.; Elías, A.; Ruiz, T.E.; Rodríguez, R. Leucaena leucocephala y un concentrado de sacharina como suplemento para hembras bovinas en crecimiento en pastizales de gramíneas de secano. Rev. cubana Cienc. agríc. 1992: 26:263. 